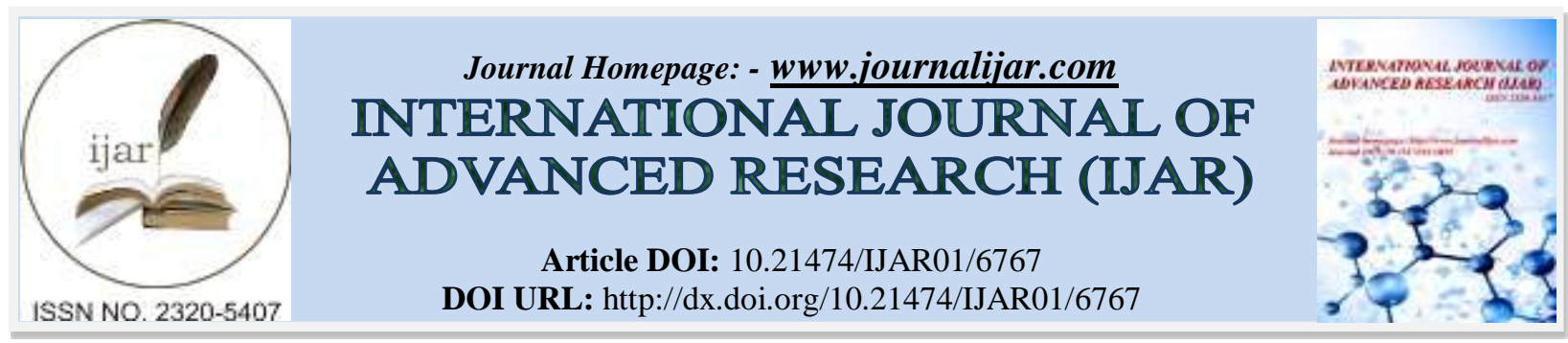

RESEARCH ARTICLE

\title{
TRIPLE VERSUS DUAL ANTIPLATELET THERAPY IN PATIENTS WITH ACUTE CORONAY SYNDROME UNDERGOING PERCUTANEOUS CORONARY INTERVENTION (PCI) IN SCB MEDICAL COLLEGE, CUTTACK, ODISHA, INDIA.
}

Routray S. N. ${ }^{1}$, Parida N. R. ${ }^{2}$, Patnaik U. K. ${ }^{1}$, Satpathy C. ${ }^{3}$, Mohanty N. K. ${ }^{3}$ and Dash B. K. ${ }^{4}$,

1. Professor, Institute of cardiovascular sciences, Dept. of Cardiology, S.C.B.Medical College, Cuttack, Odisha, India.

2. Resident, Institute of cardiovascular sciences, Dept. of Cardiology, S.C.B.Medical College, Cuttack, Odisha, India.

3. Associate professor, Institute of cardiovascular sciences, Dept. of Cardiology, S.C.B.Medical College, Cuttack, Odisha, India.

4. Assistant professor Institute of cardiovascular sciences, Dept. of Cardiology, S.C.B.Medical College, Cuttack, Odisha, India.

\section{Manuscript Info}

\section{Manuscript History}

Received: 17 January 2018

Final Accepted: 19 February 2018

Published: March 2018

\section{Abstract}

Background: It has been demonstrated in previous large randomized studies that cilostazol based triple antiplatelet therapy (TAPT) in addition to aspirin and clopidogrel based dual antiplatelet therapy (DAPT) has improved the clinical outcomes in patients undergoing percutaneous coronary intervention (PCI). Objective: The present study was conducted to compare the efficacy of triple versus dual antiplatelet therapy in patients undergoing PCI. Material and methods: We enrolled 200 consecutive acute coronary syndrome patients undergoing drug eluting stents implantation. Half of the patients $(\mathrm{n}=100)$ received dual antiplatelet therapy (aspirin plus clopidogrel); rest half( $\mathrm{n}=100)$ received triple antiplatelet therapy ( aspirin, clopidogrel plus cilostazol). The triple antiplatelet group received cilostazol at least for 1 month. The two group of patients were followed up at interval of 1,3 and 6 months for any major adverse cardiac events. The triple antiplatelet group had more bleeding manifestations than dual group. At the end of six months follow up both groups had no statistically significant difference in terms of major adverse cardiac events. Target vessel revascularization was more in in the dual than the triple antiplatelet group.

Conclusions: Triple antiplatelet therapy seems to be superior to dual antiplatelet therapy in patients undergoing PCI with drug eluting stents.

Copy Right, IJAR, 2018,. All rights reserved.

\section{Introduction:-}

Percutaneous coronary intervention (PCI), also known as coronary angioplasty, is a non-surgical method used to treat narrowed coronary arteries that supply the cardiac muscle with blood ${ }^{1}$. PCI has been clinically applied for almost 30 years and has become one of the main treatments for coronary heart disease (CHD) ${ }^{2}$. PCI with coronary stent implantation has been demonstrated to consistently reduce the symptoms of coronary artery disease and 
decrease cardiac ischemia; however, PCI has not been shown to reduce mortality rates in large clinical trials ${ }^{3}$. The implantable vascular stents used during PCI procedures appear to increase the risk of coronary artery intimal injury and platelet activation, and may thereby increase the risk of thrombosis ${ }^{4}$. This is significant, as the 1 -year mortality rate of patients with myocardial infarction (MI) induced by thrombotic diseases is $\sim 15.8 \%{ }^{5}$. Therefore, antiplatelet therapy has become the focus of basic interventional cardiology studies and has received increased clinical attention in the last decade ${ }^{6}$.

Dual antiplatelet therapy with aspirin and clopidogrel is currently the standard of care to prevent stent thrombosis after percutaneous coronary intervention with bare metal stent or drug eluting stent. ${ }^{7}$ However there is significant interindividual variability in the extent of platelet inhibition achieved with these two antiplatelet agents. ${ }^{8}$ Cilostazol is a phosphodiesterase III inhibitor, exhibits its antiplatelet effects via inhibition of the conversion of cAMP to 5'AMP causing a subsequent increase in cAMP in platelets and has been shown to augment platelet inhibition when added to aspirin and clopidogrel. In addition cilostazol inhibits neointimal hyperplasia and smooth muscle proliferation and has the potential to reduce the risk of restenosis after coronary stent implantation. Triple antiplatelet therapy with aspirin, clopidogrel and cilostazol has been tried in many trials in the era of drug eluting stents with mixed results. ${ }^{9}$ Because of its different pharmacokinetic action it may have an additive effect in patients undergoing PCI.

Registry data have further identified that TAPT reduces the rate of restenosis, incidence of clinical events and stent thrombosis, compared with DAPT ${ }^{10}$. However, controlled clinical studies that have examined the benefits of adding cilostazol to DAPT in patients with CHD undergoing PCI with coronary stent implantation have obtained conflicted or inconclusive results. Therefore, the present study is aimed to compare efficacy and differences in the clinical outcomes between DAPT and TAPT in patients with CHD undergoing PCI.

\section{Aims And Objectives:-}

To study the effect of triple antiplatelet therapy versus dual antiplatelet therapy in patients undergoing percutaneous coronary intervention by observing

1. Total number of deaths after 6 months follow up . 2. Number of cardiac deaths and major adverse cardiac events (MACE) and MACCE ( Major adverse cardiac and cerebrovascular events) at six months follow up. 3. Ischaemia driven target vessel revascularization at 6 months.

\section{Methods:}

All new consecutive acute coronary syndrome cases undergoing percutaneous coronary intervention in our institute with drug eluting stent implantation were enrolled as cases. Lesions that were hemodynamically significant i.e. more than $70 \%$ stenosis were planned for percutaneous coronary intervention using drug eluting stents.

Following PTCA patients were randomly assigned into two groups. Half of them $(n=100)$ received dual antiplatet drugs ( Aspirin and Clopidogrel) and the other half $(n=100)$ received triple antiplatelet ( Aspirin, Clopidogrel and additional Cilastazol therapy for 1 month. Various MACE and MACCE at 6 months were compared between these groups.

Inclusion criteria: Patients aged 18 years and above with acute coronary syndromes presented in cardiology department with history of chest pain and undergoing PCI.

Exclusion criteria: 1.Contraindication to aspirin, clopidogrel and cilostazol.2. Left main disease. 3. Graft versus host disease. 4. LVEF $<30 \%$.

\section{Statistical analysis:-}

The following statistical methods were applied in the present study. Frequencies, Descriptive statistics, Cross tabs procedure( contingency coefficient test), Independent samples ' $t$ ' test, Bivariate correlation, Logistic regression. Frequencies

The frequencies procedure provides statistics and graphical displays that are useful for describing many types of variables. 


\section{Descriptive}

The Descriptive procedure displays univariate summary statistics for several variables in a single table and calculates standardized values ( $\mathrm{z}$ scores). Variables can be ordered by the size of their means ( in ascending or descending order), alphabetically, or by the order in which the variables are selected.

Crosstabs

The procedure forms two way and multi way tables and provides a variety of tests and measures of association for two tables. The structure of the table whether categories are ordered determine what test or measure to use.

Independent-Samples T test

It compares means for two groups of cases. Ideally, for this test, the subjects should be randomly assigned to two groups, so that any difference in response is due to the treatment ( or lack of treatment) and not to other factors.

All the statistical analysis were done by SPSS 22 Inc. software.

\section{Ethic statement:-}

Study procedure was approved by the Institutional Ethics Committee of S.C.B. Medical College and Hospital, Cuttack, Odisha, ( Regd. No. ECR/84/Inst/OR/2013) while grant for the study was approved by the Institutional Review Board vide Ref. No. 465/31.08.2017. Written consent was sorted prior to participation from respondents by means of an informed consent. Participants were informed regarding the PCI procedure and benefits and side effects of antiplatelet therapy in appropriate format.

\section{Flow Chart}

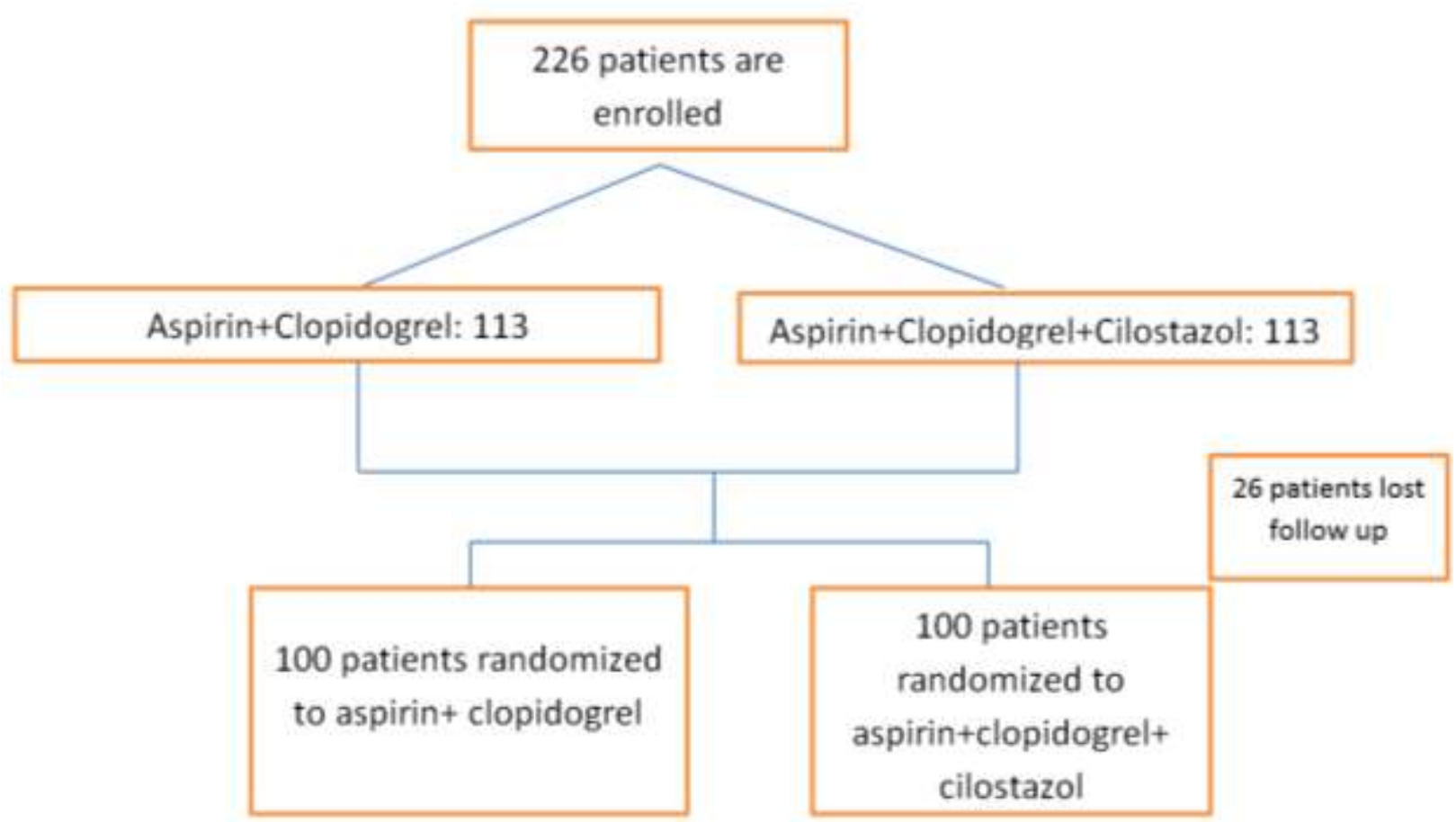

\section{Result:-}

The mean age of presentation in our study population was $63.81 \pm 8.71$ years, with maximum number of patients between 61-70 years i.e. 87 (43.5\%) number of patients, less number of patients in the age group of 41-50 years i.e. $20(10 \%)$ as shown in table1. This is supported by K.P. Alexannder, et al. ${ }^{11}$ 
Table 1

\begin{tabular}{|l|l|}
\hline Age in years & Frequency \\
\hline $\mathbf{4 1 - 5 0}$ & $20(10 \%)$ \\
\hline $\mathbf{5 1 - 6 0}$ & $67(33.5 \%)$ \\
\hline $\mathbf{6 1 - 7 0}$ & $87(43.5 \%)$ \\
\hline $\mathbf{7 1 - 8 0}$ & $26(13 \%)$ \\
\hline
\end{tabular}

In our study male predominance was observed, i.e.male patients $80 \%(\mathrm{n}=160)$ and female20\% $(\mathrm{n}=40)$ which is same as Annika Rosengren et al. 2004. ${ }^{12}$

As shown in table 2 and figure 2 maximum numbers of male patients in our study are between age group of 61-70 years i.e. $75(37.5 \%)$ and minimum between $41-50$ years i.e. 14(7\%). Maximum number of female patients are in the age group of 51-60 years i.e. 16 ( $8 \%$ ). Our observation is supported by Lozano R et al 2012. ${ }^{13}$

Table 2

\begin{tabular}{|c|c|c|}
\hline Age group & Male & Female \\
\hline $\mathbf{4 1 - 5 0}$ years & $14(7 \%)$ & $6(3 \%)$ \\
\hline $\mathbf{5 1 - 6 0}$ years & $51(25.55)$ & $16(8 \%)$ \\
\hline $\mathbf{6 1 - 7 0}$ years & $75(37.5 \%)$ & $12(6 \%)$ \\
\hline $\mathbf{7 1 - 8 0}$ years & $20(10) \%$ & $6(3 \%)$ \\
\hline
\end{tabular}

\section{Figure 2:-}

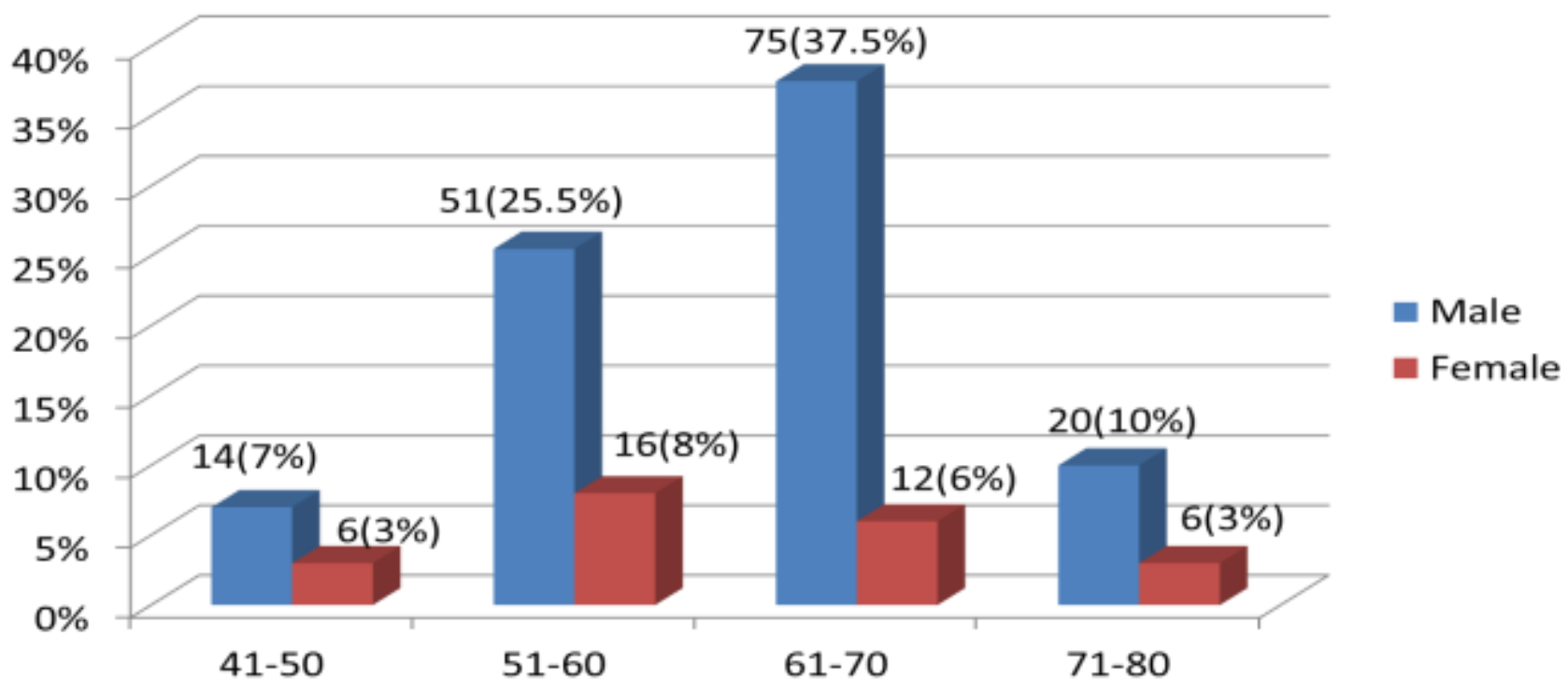

In our study as shown in table 3 maximum number of patients were having ST elevated myocardial infarction (STEMI) i.e. 134(67\%), followed by Non ST segment elevated myocardial infarction ( NSTEMI) 47(23.5\%) and only 19(9.5\%) patients have Unstable Angina (UA) which is in par with two Indian studies Eagle K et al. and Prabhakaran D et al. ${ }^{14,15}$

Table 3:-

\begin{tabular}{|c|c|}
\hline Disease & Frequency \\
\hline STEMI & $134(67 \%)$ \\
\hline NSTEMI & $47(23.5 \%)$ \\
\hline Unstable Angina & $19(9.5 \%)$ \\
\hline
\end{tabular}


In our study population as shown in table 4 and figure 4 male have more STEMI i.e. 114(71.25\%), followed by female 20(50\%), where as female patients have more NSTEMI (30\%) and Unstable Angina (20\%) which is statistically very significant $(\mathrm{p}<0.003)$ which is supported by Prescott E et al and Aliah A et al 2017. ${ }^{16,17}$

Table 4:-

\begin{tabular}{|c|c|c|}
\hline \multirow{2}{*}{ Disease } & \multicolumn{2}{|c|}{ Frequency } \\
\cline { 2 - 3 } & Male & Female \\
\hline STEMI & $114(57 \%)$ & $20(10 \%)$ \\
\hline NSTEMI & $35(17.5 \%$ & $12(6 \%)$ \\
\hline Unstable Angina & $11(5.5 \%)$ & $8(4 \%)$ \\
\hline
\end{tabular}

Figure 4:-

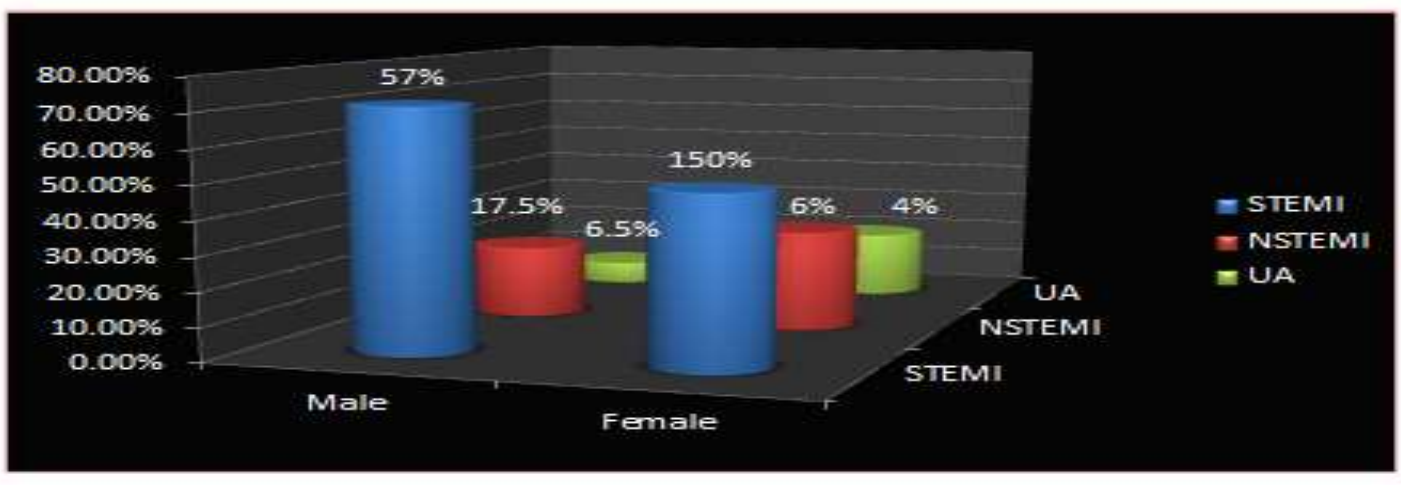

In our study more number of patients i.e.163(81.5\%) have undergone single vessel revascularisation than double vessel in $37(18.5 \%)$. Single stent was deployed in $115(57.5 \%)$, two stents in $76(38.5 \%)$ and three stents in $9(4.5 \%)$ patients of our study population.

Table 5 depicts the follow up symptoms at 1,3 and 6 months follow up. Most patients were asymptomatic at follow up visits same supported by Fischman DL et al ${ }^{18}$, followed by chest pain and bleeding manifestations. Fatal myocardial infarction was observed in $4(2 \%)$ at 1 month, 3(1.5\%) at 3 months, and 7(3.5\%) at 6 months follow up. Randomized studies have revealed 6-month rates of angiographically demonstrated restenosis ranging from $32 \%$ to $42 \%$ after balloon angioplasty and from $16 \%$ to $32 \%$ after the implantation of a non-drug-eluting stent (bare metal stent, BMS) ; the 6-month rate of restenosis after the implantation of a drug-eluting stent is less than $10 \%$ contrary to our study Serruys PW et al.$^{19}$

Table 5:-

\begin{tabular}{|l|l|l|l|}
\hline Symptoms & 1 month follow up & 3 month follow up & 6 month follow up \\
\hline Chest pain & $22(11 \%)$ & $14(7 \%)$ & $11(5.5 \%)$ \\
\hline $\begin{array}{l}\text { TIMI major Bleeding } \\
\text { manifestation }\end{array}$ & $14(7 \%)$ & $17(8.5 \%)$ & $17(8.5 \%)$ \\
\hline Nonfatal MI & $2(1 \%)$ & $3(1.5 \%)$ & $12(6 \%)$ \\
\hline Fatal MI & $4(2 \%)$ & $3(1.5 \%)$ & $7(3.5 \%)$ \\
\hline Asymptomatic & $158(79 \%)$ & $163(81.5 \%)$ & $153(76.5 \%)$ \\
\hline
\end{tabular}

DAPT group have more major adverse cardiac events (MACE) than TAPT group. But the analysis was statistically insignificant ( $\mathrm{p}$ < 0.087). Our observation is supported by Ahn Y et al. ${ }^{20}$

In our study cohort correlation of dual versus triple antiplatelet therapy in terms of follow up symptoms like chest pain, fatal and nonfatal myocardial infarction, Chest pain and myocardial infarction was more in the dual antiplatelet (DAPT) group while TIMI major and minor bleeding manifestation was high in the triple antiplatelet (TAPT) group (shown in Table 6) which is statistically significant $(\mathrm{p}<0.008)$ which is supported by Young-Hoon et al. ${ }^{21}$ 
Table 6:-

\begin{tabular}{|c|c|c|c|c|c|c|c|}
\hline \multirow[t]{3}{*}{ Anti platelet } & \multicolumn{7}{|c|}{ Symptoms } \\
\hline & \multirow[t]{2}{*}{$\begin{array}{l}\text { Chest } \\
\text { pain }\end{array}$} & $\begin{array}{l}\text { TIMI } \\
\text { manife }\end{array}$ & $\begin{array}{l}\text { Bleeding } \\
\text { ns }\end{array}$ & \multirow[t]{2}{*}{$\begin{array}{l}\text { Nonfatal } \\
\text { MI }\end{array}$} & \multirow[t]{2}{*}{$\begin{array}{l}\text { Fatal } \\
\text { MI }\end{array}$} & \multirow[t]{2}{*}{ None } & \multirow[t]{2}{*}{ Total } \\
\hline & & Minor & Major & & & & \\
\hline Aspirin+Clopidogrel & 7 & 2 & 0 & 3 & 2 & 86 & 100 \\
\hline Aspirin+Clopidogrel+Cilostazol & 7 & 13 & 2 & 0 & 1 & 77 & 100 \\
\hline Total & 14 & 15 & 2 & 3 & 3 & 163 & 200 \\
\hline
\end{tabular}

The linear regression values of antiplatelet therapy in relation to target vessel revascularization showed that TAPT group had less TVR than DAPT which is statistically not significant which is similar to Lee CH, et al.( DECREASE PCI-trial) and contrary to the observation by Sripal Bangalore et al. ${ }^{22}$

More the number of stents deployed more is the MACE which was statistically highly significant $(p<0.001)$. Our study is supported by James $\mathbf{E}$ et $\mathbf{a l}{ }^{23-25}$

\section{Discussion:-}

In this prospective randomized study the efficacy of cilostazol as antiplatelet was compared with that of conventional dual antiplatelet drugs aspirin and clopidogrel in patients undergoing PCI. The results showed that in the triple antiplatelet therapy arm there was more bleeding risk. In terms of MACE triple antiplatelet therapy does not significantly score over DAPT. In follow up visits patients on DAPT had more history of chest pain, nonfatal. Stent thrombosis is a major concern for DES, cilostazol does not appear to provide benefit which shoud be interpreted cautiously in further large randomized studies. There was no statistically significant difference in the two groups in terms of TVR and TLR. The antiproliferative properties of cilostazol may have contributed to this beneficial effect. The limitations of this study was less number of patients enrolled and further follow up till one year could have added more information regarding efficacy.

\section{Conclusion:-}

Triple therapy with cilostazol has been shown to reduce MACEs by providing increased inhibition of platelet aggregation and reducing the rates of in-stent thrombosis compared to DAPT without increasing the risk of bleeding. Compared with DAPT, patients with a high risk of restenosis benefited from TAPT in reduced stent restenosis and revascularization after DES implantation, without increases in all-cause mortality and bleeding, but these outcomes were accompanied by a higher incidence of other adverse reactions and drug discontinuation. Further studies are needed to identify proper patient selection based on risk factors for the addition of cilostazol. Additionally, studies comparing cilostazol with newer antiplatelet therapies, such as prasugrel and ticagrelor, are needed.

\section{Bibilography:-}

1. Aradi D, Komócsi A, Price MJ, et al. Efficacy and safety of intensified antiplatelet therapy on the basis of platelet reactivity testing in patients after percutaneous coronary intervention: Systematic review and metaanalysis. Int J Cardiol. 2012 Jun 15; (Epub ahead of print) [PubMed].

2. Meryon I, Patel N, Millane T, Varma C. Normal coronary angiography and primary percutaneous coronary intervention for ST elevation myocardial infarction: a literature review and audit findings. Int J Clin Pract. 2010;64:1245-1251. [PubMed].

3. Mercado N, Serruys PW et al. A meta-analytical approach for the treatment of in-stent restenosis. Eur Heart J. 2003;24:217-218.

4. Meier B, Bachmann D, Lüscher T. 25 years of coronary angioplasty: almost a fairy tale. Lancet. 2003;361:527.

5. Mrdovic I, Savic L, Lasica R, et al. Usefulness of the RISK-PCI score to predict stent thrombosis in patients treated with primary percutaneous coronary intervention for ST-segment elevation myocardial infarction: a substudy of the RISK-PCI trial. Heart Vessels. 2013;28:424-433.

6. Gurbel PA, Tantry US. Aspirin and clopidogrel resistance: consideration and management. J Interv Cardiol. 2006;19:439-448.

7. Laura Mauri and Deepak L. Bhatt, Braunwald's Heart disease 10th edition, volume 2, chapter 55, page 1255.

8. Serebruany VL, Steinhubl SR, Berger PBet al. Variability in platelet responsiveness to clopidogrel among 544 individuals, J Am Coll Cardiol 2005;45:246-51.

9. Jung-Who Suh et al: Journal of the college of cardiology 2011 Jan 18;57 (3): 280-9. 
10. Lee SW, Park SW, Hong MK, et al. Triple versus dual antiplatelet therapy after coronary stenting: impact on stent thrombosis. J Am Coll Cardiol. 2005;46:1833-1837.

11. K.P. Alexannder, et al. Acute coronary care in the elderly, part I: non-ST-segment-elevation acute coronary syndromes: a scientific statement for healthcare professionals from the American Heart Association Council on Clinical Cardiology: in collaboration with the Society of Geriatric Cardiology Circulation, 115 (19) (2007), pp. 2549-2569.

12. Annika Rosengren Lars Wallentin Anselm K. Gitt Solomon Behar Alexander Battler David Hasdai. Sex, age, and clinical presentation of acute coronary syndromes European Heart Journal, Volume 25, Issue 8, 1 April 2004, Pages 663-670.

13. Lozano R, Naghavi M, Foreman K, et al. Global and regional mortality from 235 causes of death for 20 age groups in 1990 and 2010: a systematic analysis for the Global Burden of Disease Study 2010. Lancet. 2012;380:2095-2128.

14. Eagle K. Coronary artery disease in India: challenges and opportunities. Lancet. Apr 26 2008;371(9622):13941395.

15. Prabhakaran D, Yusuf S, Mehta S, et al. Two-year outcomes in patients admitted with non-ST elevation acute coronary syndrome: results of the OASIS registry 1 and 2. Indian Heart J. May-Jun 2005;57(3):217-225.

16. Prescott E, Hippe M, Schnohr P, Hein HO, Vestbo J. Smoking and risk of myocardial infarction in women and men: longitudinal population study. BMJ. 1998; 316:1043-7.

17. Heart Views. 2017 Jul-Sep; 18(3): 77-82. doi: 10.4103/HEARTVIEWS.HEARTVIEWS_10_17

18. Aliah Ali Khesroh et al. Gender Differences among Patients with Acute Coronary Syndrome in the Middle East. PMCID: PMC5686932.

19. Fischman DL, Leon MB, Baim DS, et al. A randomized comparison of coronary-stent placement and balloon angioplasty in the treatment of coronary artery disease. Stent Restenosis Study Investigators. N Engl J Med. 1994;331:496-501.

20. Serruys PW, de Jaegere P, Kiemeneij F, et al. A comparison of balloon-expandable-stent implantation with balloon angioplasty in patients with coronary artery disease. Benestent Study Group. N Engl J Med. 1994;331:489-495.

21. Ahn Y1, Jeong MH, Jeong JW, Kim KH, Ahn TH, Kang WC, Park CG, Kim JH, Chae IH, Nam CW, Hur SH, Bae JH, Kim KY, Oh SK. Randomized comparison of cilostazol vs clopidogrel after drug-eluting stenting in diabetic patients--clilostazol for diabetic patients in drug-eluting stent (CIDES) trial. Circ J. 2008 Jan;72(1):359.

22. Young-Hoon Jeong MD, PhD, Seung-WhanLeeMD, PhD :Randomized Comparison of Adjunctive Cilostazol Versus High Maintenance Dose Clopidogrel in Patients With High Post-Treatment Platelet Reactivity: Results of the ACCEL-RESISTANCE (Adjunctive Cilostazol Versus High Maintenance Dose Clopidogrel in Patients With Clopidogrel Resistance) Randomized Study, Clinical Research Interventional Cardiology, Journal of the American College of Cardiology, Volume 53, Issue 13, 31 March 2009, Pages 1101-1109.

23. Sripal Bangalore, Amita Singh, Bora Toklu, James J DiNicolantonio, Kevin Croce, Frederick Feit and Deepak L Bhatt, Efficacy of cilostazol on platelet reactivity and cardiovascular outcomes in patients undergoing percutaneous coronary intervention: insights from a meta-analysis of randomised trials. Heart Asia, BMJ, vol 1 , Issue 1.

24. Seung-WhanLee, Seong-WookPark, Myeong-KiHong, Cheol WhanLee, Comparison of cilostazol and clopidogrel after successful coronary stenting,.amjcard.2004.12.012.

25. James E. Tcheng, MD; Ing Haan Lim,Stent Parameters Predict Major Adverse Clinical Events and the Response to Platelet Glycoprotein IIb/IIIa Blockade ,Findings of the ESPRIT Trial, Circ. Cardiovasc Intervent. 2009;2:43-51.

26. Lee $\mathrm{CH}$, et al. DECREASE-PCI: Triple antiplatelet therapy reduces TVR after DES implantation. Am J Cardiol. 201;doi:10.1016/j.amjcard.2017.11.005. January 29, 2018. 